\title{
Local and remote SST variability contribute to the westward shift of the Pacific Walker circulation during 1979-2015
}

\author{
Xichen $\mathrm{Li}^{1,2^{*}} \mathbb{0}$, Xinyue Wang ${ }^{1,3}$, Tao Lian ${ }^{2,4,5}$, Nathaniel C. Johnson ${ }^{6}$, Jiang Zhu ${ }^{1,3}$, Chueh-Hsin Chang ${ }^{7}$, \\ Hailong Liu ${ }^{1}$ and Wenzhu Wang ${ }^{1,3}$
}

\begin{abstract}
During the modern satellite era since 1979, the Pacific Walker circulation (PWC) experienced an intensification and a westward shift, which has broad impacts on the global climate variability. While the strengthening of the PWC has been shown to be driven by both the regional Pacific sea surface temperature (SST) and the remote forcing from other basins, its westward shift is primarily attributed to the phase change of the Atlantic Multidecadal variability. In this study, we investigate the potential effect of the remote SST forcing from the Atlantic and the Indian Oceans on the westward shift of the PWC, through statistical analysis and numerical experiments using atmospheric and coupled models. Results show that the tropical Atlantic warming plays a key (decisive) role in driving the PWC westward shift by triggering a Gill-Matsuno-type circulation anomaly in the tropics. This circulation response drives anomalous surface westerlies over the eastern Pacific and subsidence over the central Pacific that weakens the eastern part of the PWC, meanwhile generating easterly wind anomalies over the central-western Pacific and anomalous atmospheric convection over the western Pacific that intensifies the western part of the PWC. This direct forcing contributes 32\% of the observed PWC movement, while the Atlantic-induced inter-basin SST changes contribute another 36\% of its westward shift according to coupled model simulation results. Our results reinforce the importance of the inter-basin interactions in adjusting the tropical climate variabilities, and have broad implication for projecting the global climate.
\end{abstract}

Keywords: Pacific Walker circulation, Inter-basin interaction, Atlantic multi-decadal oscillation, Atmosphere-ocean interaction

\section{Introduction}

The Pacific Walker circulation (PWC) is a key component of the tropical and global climate system. It is a large-scale atmospheric overturning circulation (Bjerknes 1969), characterized by westward surface trade winds over the equatorial Pacific, deep convection over the Indo-western Pacific, and subsidence over the centraleastern Pacific. The PWC plays an important role in the regional atmosphere-ocean interactions (Rasmusson

\footnotetext{
*Correspondence: lixichen@mail.iap.ac.cn

${ }^{1}$ Institute of Atmospheric Physics, Chinese Academy of Sciences, Beijing, China

Full list of author information is available at the end of the article
}

and Carpenter 1982; Timmermann et al. 2018). It drives the circulation in the upper ocean (Lee et al. 2013; Hu et al. 2015), impacts the atmosphere-ocean heat fluxes by adjusting the surface wind speed and thus the evaporation (Xie and Philander 1994), and responds to the sea surface temperature (SST) gradient over the tropics (Lindzen and Nigam 1987; Zhang and Karnauskas 2017). Moreover, the PWC mediates the interactions between different ocean basins (Alexander et al. 2002; Cai et al. 2019), and between the climate variability in the tropical ocean and that over the mid- and high-latitudes (Horel and Wallace 1981; England et al. 2014), thus having broad impacts on the global climate system (Kosaka and Xie 2013). 
Previous studies describe a projected long-term weakening and eastward shift of the PWC (Zhang and Song 2006; Bayr et al. 2014) under the anthropogenic greenhouse gas warming. It balances the tendency of the hydrological cycle caused by the different increasing rates between water vapor and precipitation under global warming (Held and Soden 2006; Power and Kociuba 2011). This PWC slow-down has been validated by both long-term observations (Vecchi et al. 2006; Tokinaga et al. 2012) and coupled model simulations (Knutson and Manabe 1995; DiNezio et al. 2013).

However, during the modern satellite era since 1979, the observed PWC has strengthened (L'Heureux et al. 2013), associated with an intensification of the Pacific trade wind (Li and Ren 2012; De Boisséson et al. 2014). These circulation changes have been primarily attributed to natural variability rather than anthropogenic forcing (Chung et al. 2019), and is tightly associated with the local SST gradient (Seager et al. 2019). In particular, the phase change of the interdecadal Pacific oscillation (IPO) has been reported to largely contribute to the recent PWC trends (Meehl et al. 2013). In addition, remote forcing from the Atlantic (Wang 2006; McGregor et al. 2014; Li et al. 2016; Ruprich-Robert et al. 2017) and the Indian Ocean (Luo et al. 2012) also play important roles in strengthening the PWC through tropical inter-basin interactions (Kucharski et al. 2011; Cai et al. 2019). For example, the north and tropical Atlantic warming caused by the combined effects of anthropogenic forcing (Xie et al. 2010; Booth et al. 2012) and the change in meridional overturning circulation (Schlesinger and Ramankutty 1994) may heat the Indian Ocean (Li et al. 2016) and trigger the phase change of the IPO (Zhang and Delworth 2009; Kucharski et al. 2016), both intensifying the PWC (McGregor et al. 2014).

Accompanied with its intensification in the past four decades, a robust westward shift of the PWC has been detected through statistical analysis using seven reanalysis datasets (Ma and Zhou 2016). This westward shift of PWC has broad impacts on the tropical climate, drying Eastern Africa (Williams and Funk 2011) and driving the tropical sea level changes (Merrifield 2011). Similar to its intensification, the westward shift of the PWC is also primarily attributed to natural variability of the tropical SST (Chung et al. 2019). Statistical analysis and numerical simulations (Kim and Ha 2018) reveal that the phase change of the IPO may dominate the physical processes that cause the westward shift of the PWC since late 1950s.

Nevertheless, the role of inter-basin interactions in the PWC variability has yet to be systematically investigated, especially during the modern satellite era since 1979, when the Atlantic multi-decadal oscillation (AMO) started its ascending mode and has been reported to trigger the decadal variability of the Indian and Pacific Oceans (Zhang and Delworth 2007). In this study, we investigate the regional and remote forcing of the tropical SST variability on the PWC since 1979. We simulate the direct effect of the SST forcing over each ocean basin with an atmospheric general circulation model. Results show that the IPO contributed to both the intensity and the westward shift of the PWC, whereas the AMO contributed to a considerable part of its westward shift. We then incorporate the air-sea interaction and inter-basin interaction with pacemaker simulations using an earth system model. The Atlantic warming and its induced pan-tropical SST variability are found to largely contribute to the intensification and the westward shift of the PWC. The details are discussed in the following text.

\section{Data and method}

\section{Observational and reanalysis datasets}

The UK Met Office Hadley Centre's SST dataset (HadISST, Rayner et al. 2003) is used in this study to evaluate the global SST trend between 1979 and 2015, and to drive the atmospheric model.

We use six reanalysis datasets: (1) the Twentieth Century Reanalysis (20CR; Compo et al. 2011); (2) the Interim reanalysis data from the European Centre for Medium-Range Weather Forecasts (ERA-interim; Dee et al. 2011); (3) the Japanese 55-year Reanalysis (JRA55; Kobayashi et al. 2015); (4) the Modern-Era Retrospective analysis for Research and Applications (MERRA; Rienecker et al. 2011); (5) the MERRA version-2 (MERRA2); and (6) the NCEP-DOE Reanalysis version-2 (NCEP2; Kanamitsu et al. 2002).

The monthly mean horizontal wind velocity (the zonal and the meridional components: $U$ and $V$ ), the geopotential height, and the precipitation data of each reanalysis are used in the analysis. Moreover, the ensemble-average of these reanalysis datasets are calculated to investigate the westward shift of the PWC and its related physical processes.

\section{Mass stream function of the PWC}

The zonal mass stream function (e.g., Fig. 1a) is used to define the intensity and the location of the PWC. The mass stream function is calculated by vertically integrating the meridional-mean (between $5^{\circ} \mathrm{S}$ and $5^{\circ} \mathrm{N}$ ) divergent component of the zonal velocity $(U)$, as used in several previous studies (Yu and Zwiers 2010). The detailed formula is listed as follows:

$$
\Psi=\frac{a \Delta \varphi}{g} \int_{0}^{p} u_{\mathrm{D}} d p
$$



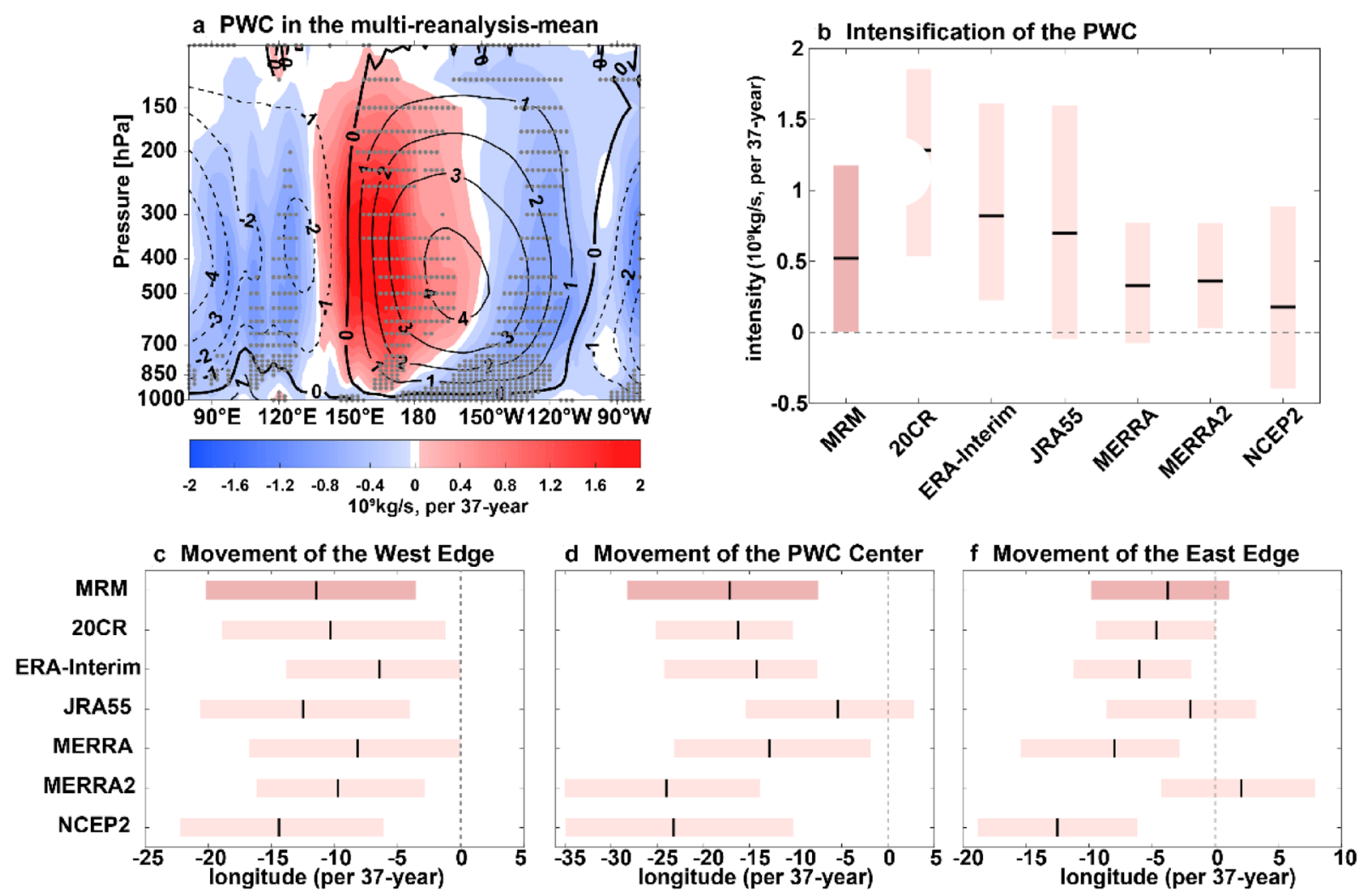

Fig. 1 The changes of the Pacific Walker circulation (PWC) in reanalysis datasets. a Shows the climatology (contours) and the trend (color shading) of the PWC from 1979 to 2015 in the ensemble-mean of six reanalysis datasets. The gray dots represent the areas with confidence level of 95\%. b Quantifies the total trend (change in 37 years from 1979 to 2015) of the PWC in the multi-reanalysis-mean (MRM) and each of the six reanalyses, with black bars showing the amplitude of the trend and the error bars indicating its 95\% confidence intervals. c-e Quantify the westward shifts of the west edge (c), the center (d), and the east edge (e) of the PWC

where $\Psi$ is the mass stream function, $a$ is the radius of the earth, $\Delta \varphi=2 \pi * 10 / 360$ is the radian between $5^{\circ} \mathrm{S}$ and $5^{\circ} \mathrm{N}, p$ is the pressure, and $u_{\mathrm{D}}$ is the divergent component of the zonal wind $(U)$, which is calculated by solving the Poisson equation for the velocity potential function.

\section{Statistical analysis}

The intensity of the anomalous PWC is defined as the vertically and zonally averaged mass stream function over the central-western Pacific, between $150^{\circ} \mathrm{E}$ and $150^{\circ} \mathrm{W}$, the main area with a positive observed trend of the PWC.

Three indices are used to evaluate the position of the PWC, namely the west edge, the center, and the east edge. Since the core of PWC lies in mid-troposphere, we first average the mass stream function between 400 and $600 \mathrm{hPa}$. The west (east) edge is defined as the longitude over the western (eastern) Pacific between $90^{\circ} \mathrm{E}$ and $180^{\circ}\left(180^{\circ} \mathrm{E}\right.$ and $\left.90^{\circ} \mathrm{W}\right)$ where the integrated mass stream function reaches zero. The center of the PWC is defined as the longitude with the maximum value of the integrated mass stream function over the entire Pacific.
The longitude with the maximum value of the meridionally averaged (between $5^{\circ} \mathrm{S}$ and $5^{\circ} \mathrm{N}$ ) surface easterly wind over the Pacific basin is used to calculate the movement of the trade winds.

We use the Sen's slope (Sen 1968) method to calculate the trends of the PWC, with confidence intervals estimated using the Mann-Kendall test (Richard 1987). Student's $t$-test is also used to calculate the statistical significance of the simulation results. Before calculating the movement of the PWC, a 3-year smoothing average of the PWC location metrics has been conducted to reduce the impact of the strong interannual variabilities (Wang et al. 2013; Ma and Zhou 2016).

\section{Atmospheric model experiment}

We use the National Center for Atmospheric Research (NCAR) Community Atmospheric Model version 5 (CAM5; Neale et al. 2013) with a horizontal resolution of $\sim 2^{\circ}$ (F19), to simulate the direct effect of the tropical SST anomalies in driving the PWC variability. 
We perform four ensemble experiments, driven by the SST variability over the tropical Atlantic (the area between $20^{\circ} \mathrm{S}$ and $20^{\circ} \mathrm{N}$, as shown in Fig. 2a, surrounded by blue curves) with a $10^{\circ}$ linear buffer zone over each hemisphere (Fig. 2a, dashed blue curves), the tropical Indian Ocean (green curves), the tropical Pacific (yellow curves), and the entire tropical ocean, respectively.

Each experiment has 12 ensemble members, with the SST forcing over the target basin (e.g., the tropical Atlantic) following the observed variability from 1979 to 2015 , and the SST forcing over the other ocean areas fixed to the climatological value. The ensemble-mean of the 12 members in each experiment is used to calculate the responses of the PWC to the SST variabilities over different tropical basins.

\section{Pacemaker experiment with earth system model}

We use the NCAR Community Earth System Model version 1.06 (CESM1.06; Hurrell et al. 2013) to simulate the impacts of the tropical SST on the changes in the PWC through atmosphere-ocean interactions and inter-basin interactions.

We perform three pacemaker experiments to simulate the impacts of the Atlantic, the Pacific and the Indian Ocean, respectively. Each experiment includes a control run and a sensitivity run, both of which are integrated for 120 years. In the sensitivity run, the ocean mixedlayer temperature over the target basin (e.g., the Atlantic) is restored following the observed SST changes from 1979 to 2015 . The region in the target basin is from $20^{\circ} \mathrm{S}$ to $20^{\circ} \mathrm{N}$. Two linear buffer zones are $30^{\circ} \mathrm{S}-20^{\circ} \mathrm{S}$ and $20^{\circ} \mathrm{N}-30^{\circ} \mathrm{N}$.

$$
F=c D\left(T_{\mathrm{r}}-T_{\mathrm{m}}\right) / \tau
$$

where $c$ is the heat content of ocean water, $D$ is the mixed-layer depth, $T_{\mathrm{r}}$ is the restoring target temperature, $T_{\mathrm{m}}$ is the model temperature at each time step, and $\tau$ is the restoring time scale, set as 10 days in this study. By adding an external heating $F$ to the mixed layer of the target basin, we force the model to mimic the observed SST changes over the target basin. The simulated circulation changes in the sensitivity experiment in comparison to that of the control run thus represent the model response to the SST changes in a coupled climate system.

\section{Results}

\section{The westward shift of the PWC}

Recent studies revealed that the PWC has been intensified (L'Heureux et al. 2013) during the satellite era, accompanied with a robust westward shift (Ma and Zhou 2016). To investigate the physical mechanisms of this process, we first calculate the climatological mass stream function of the PWC and its linear trend from 1979 to 2015 using the ensemble-mean of the six reanalysis datasets, which serves as a benchmark of the numerical experiments.

The climatological PWC (contours in Fig. 1a) is located over the central-western Pacific from $150^{\circ} \mathrm{E}$ to $120^{\circ} \mathrm{W}$, with the maximum intensity occurring around $400 \mathrm{hPa}$ to $600 \mathrm{hPa}$ and between the international dateline and
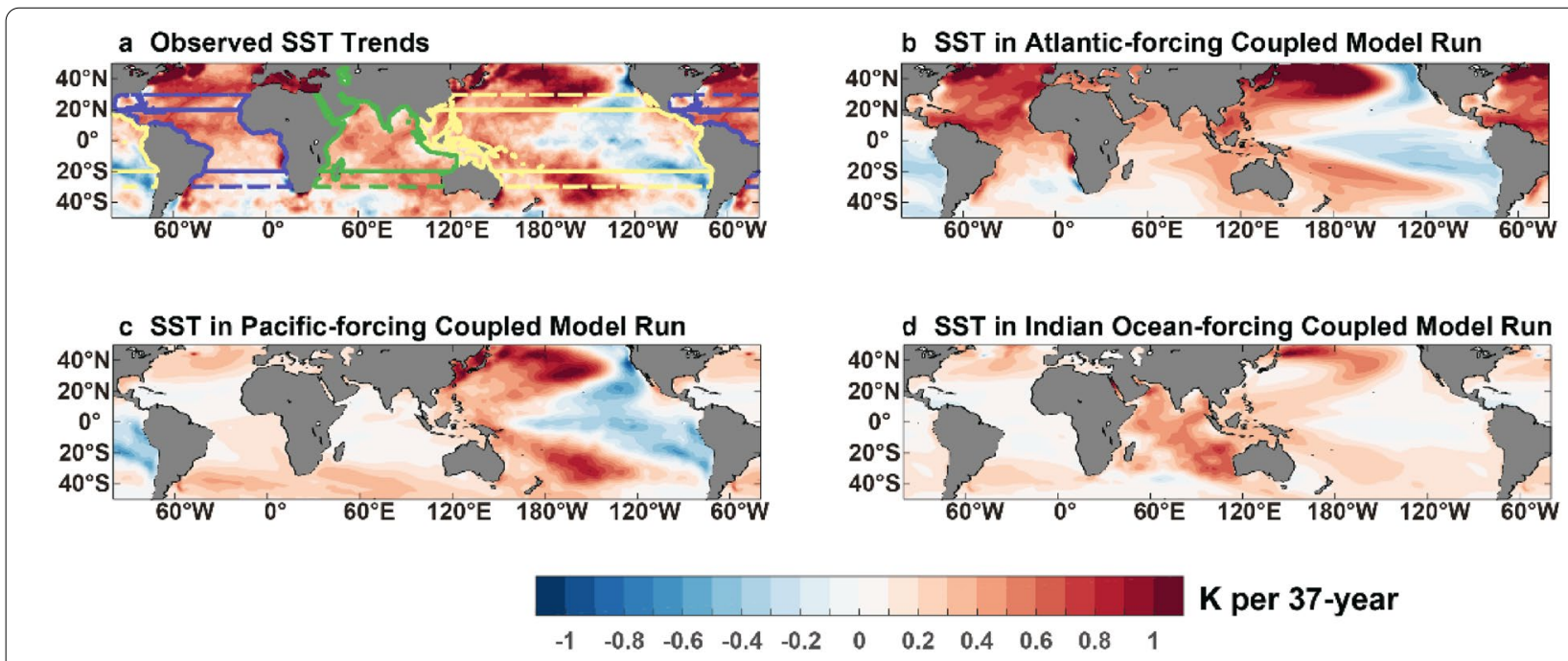

Fig. 2 The observed and the simulated changes of the tropical SST from 1979 to 2015. a shows the observed SST changes in the Hadley SST dataset, with the blue, green and yellow contours indicating the forcing area of the Atlantic-, the Indian Ocean- and the Pacific-atmospheric model simulations. b Shows simulated SST changes in the pacemaker experiment driven by the Atlantic SST forcing using the earth system model. $\mathbf{c}$ Shows simulated SST changes in the pacemaker experiment driven by the Pacific SST forcing using the earth system model. $\mathbf{d}$ Shows simulated SST changes in the pacemaker experiment driven by the Indian Ocean SST forcing using the earth system model 
$150^{\circ} \mathrm{W}$. In recent decades, a significant positive (clockwise) trend of the PWC (red in Fig. 1a) appeared to the west of $150^{\circ} \mathrm{W}$, with a negative trend (anticlockwise, blue in Fig. 1a) appearing between $150^{\circ} \mathrm{W}$ and $120^{\circ} \mathrm{W}$. This indicates a strengthening of the central and western part of the PWC accompanied with a weakening of the eastern part of the PWC, which represents an intensification and westward movement of the PWC. This result agrees well with Ma and Zhou (2016). The trend of the PWC is significant in all six reanalyses (Additional file 1: Fig. S1), although the negative trend over the eastern Pacific in MERRA2 is weaker than that in the others.

We further quantify the linear trend of the PWC in these reanalyses. The PWC in the multi-reanalysis-mean is intensified by $(0.52 \pm 0.58) \times 10^{9} \mathrm{~kg} / \mathrm{s}$ (per 37 years, Fig. 1b), about $12 \%$ of the amplitude of its climatological value. Three measures, namely the west edge, the center (maximum stream function value), and the east edge, are used to define the location of the PWC stream function. The west edge (Fig. 1c) shifted by $11.4 \pm 8.3^{\circ}$ to the west in the multi-reanalysis-mean data during 1979-2015 (Fig. 1a), with a small variation from $8.2^{\circ}$ to $14.4^{\circ}$ among different reanalyses. The center of the PWC moved by
$17.1 \pm 10.3^{\circ}$ to the west (Fig. 1d), while the east edge shifted by $3.8 \pm 5.5^{\circ}$ (Fig. 1e). Although diversities appear among different reanalyses, most of them show a significant westward trend, proving a robust westward shift of the PWC during the satellite era.

Trade wind is the surface part of PWC. In addition, surface wind plays important roles in mediating the interactions between the atmosphere and ocean. As an important proxy of the PWC, the climatology (contour) and the trend (color) of the tropical Pacific zonal wind are presented in Fig. 3a (multi-reanalysis-mean). The strongest easterly (blue color) anomaly appears over the equatorial central-western Pacific, to the west of the dateline. In contrast, a relatively weaker but significant westerly (orange) anomaly appears over the equatorial eastern Pacific, to the east of $150^{\circ} \mathrm{W}$. Superimposed on the climatological wind field, these anomalies represent a westward shift of the Pacific trade winds, tightly associated with the movement of the PWC. Similar features are observed in all six reanalyses (Additional file 1: Fig. S2). We further quantify the westward shift of the trade wind [defined by the maximum velocity of easterly wind over the tropical eastern Pacific $\left(5^{\circ} \mathrm{S}-5^{\circ} \mathrm{N}, 180^{\circ} \mathrm{W}\right.$ and
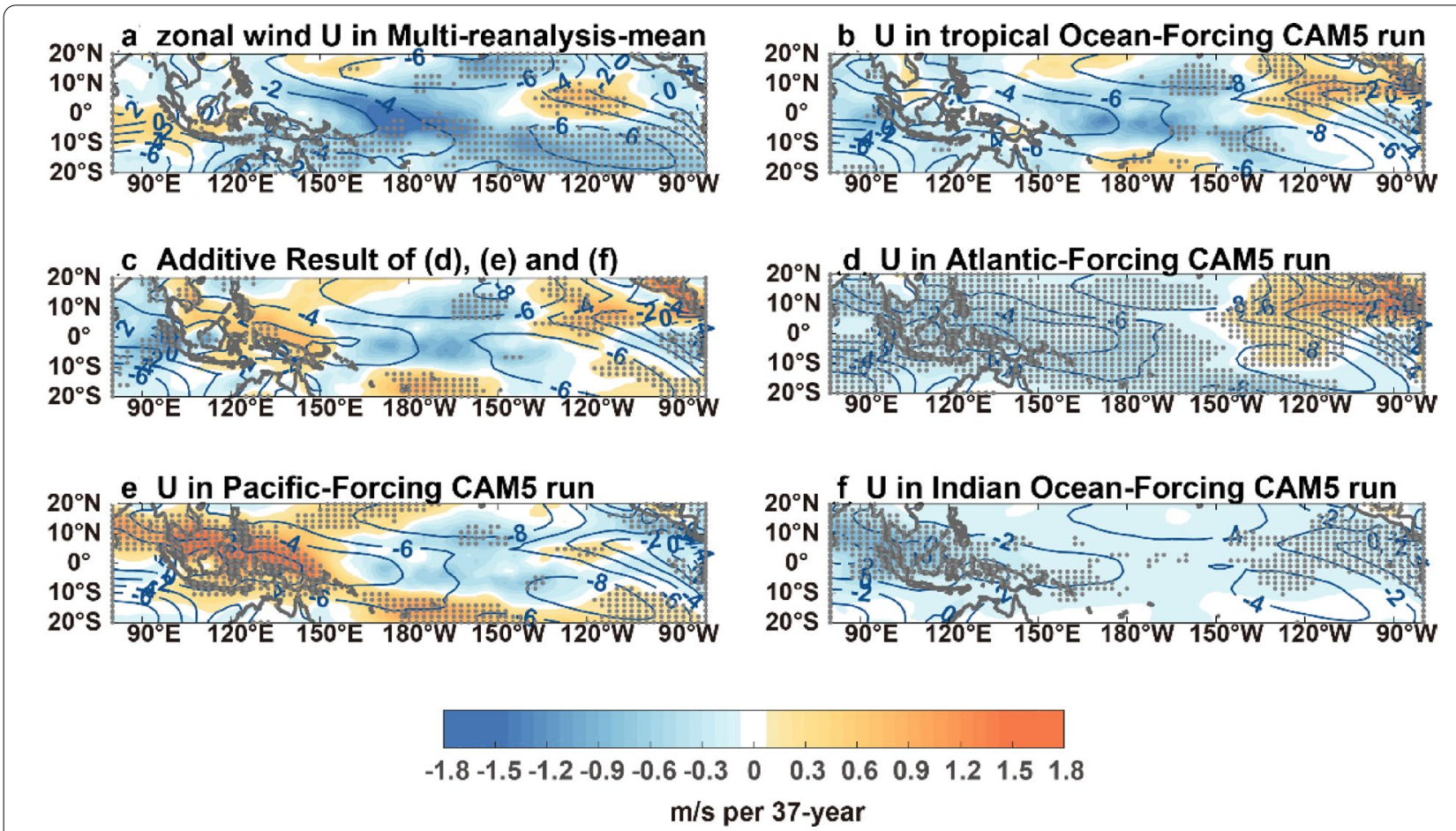

Fig. 3 The observed and simulated trends of the surface zonal wind over the tropical Pacific. a Shows the surface zonal wind climatology (contours) and its trend (color) from 1979 to 2015 in the ensemble-mean of six reanalysis datasets. The gray dots represent the areas with confidence level of 95\%. b Shows the simulated zonal wind trend in the pan-tropical-ocean forcing atmospheric model experiments, with $\mathbf{d}$-f showing the simulated zonal wind trends in the tropical Atlantic-, the tropical Pacific-, and the Indian Ocean-forcing experiments. c Shows the sum of results in $\mathbf{d}-\mathbf{f}$, which is very similar to the model results driven by the pan-tropical-oceans (b), implying the linearity between the SST forcings from different tropical ocean basins 
$\left.105^{\circ} \mathrm{W}\right)$ ], and find show a significant westward shift of about $15.2 \pm 6.6^{\circ}$ in the multi-reanalysis-mean, with a range from $7.5^{\circ}$ to $27.9^{\circ}$ among different datasets (Additional file 1: Fig. S3a). Accordingly, convergence center (purple) at lower levels (1000 hPa) extends westward to the Maritime Continent (Additional file 1: Fig. S4a).

\section{Linearity of the simulated PWC response to the tropical SST forcing}

We further investigate the effect of the tropical SST forcing in driving the observed intensification and movement of the PWC with the CAM5 simulation. During the modern satellite era from 1979 to 2015, the AMO transitioned to a positive phase with a warming trend over the north and tropical Atlantic (Fig. 2a). The Indian Ocean experienced a basin-scale warming trend, while the SST trend over the Pacific resembles a negative phase of the IPO, with a La Niña-type cooling over the central-eastern equatorial Pacific.

We first perform an atmospheric model experiment driven by the observed SST variability over the entire tropical ocean (see "Data and method"). The simulated PWC response to the observed tropical SST forcing is shown in Fig. 4a, and is characterized by a positive trend (red, clockwise) of the PWC to the west of $150^{\circ} \mathrm{W}$, and a negative trend (blue, anticlockwise) to the east of $150^{\circ} \mathrm{W}$, well reproducing the observed trend of the PWC (Fig. 1a).

We then conduct three additional atmospheric model experiments by dividing the topical SST forcing into three ocean basins: the tropical Atlantic, the Indian Ocean, and the tropical Pacific (see Fig. 2a). In each experiment, the atmospheric model is driven by the SST variability over only one ocean basin. We evaluate the linearity of the PWC response to the tropical SST forcings in CAM5 by adding the model responses of these three experiments (Fig. 4b), and comparing the additive result with the simulated PWC response in the entire-tropical forcing experiment (Fig. 4a). We find that the former resembles the latter surprisingly well, implying a linear relationship between the forcings from different ocean basins, which allows us to quantify the impacts from different ocean basins using these simulation results.

\section{Movement of the PWC driven by different basins}

We thus evaluate the impacts of the SST variability from each ocean basin (Fig. 4d-f) on the change of PWC. Both the Atlantic-forcing and the Pacific-forcing experiments produce a westward shift of the stream function (Fig. 4d, e). The Pacific-forcing drives a stronger intensification (red in Fig. 4e) of the stream function west to the dateline, whereas the Atlantic-forcing drives a stronger weakening of the PWC (blue in Fig. 4d) east to the dateline.
Both the Pacific- and the Atlantic-forcing simulations strengthen the PWC (Fig. 4c), contributing to a total intensification of about $0.54 \times 10^{9} \mathrm{~kg} / \mathrm{s}$, comparable to the observed PWC trend (Fig. 1b).

We further quantify the degree of the westward shift of the PWC driven by different ocean basins. The tropical Atlantic warming drives a robust westward shift of all three measures (Fig. 4g, the west edge; Fig. 4h, the center; and Fig. 4i, the east edge) of the PWC, while the Pacific-forcing drives a westward shift of the center of the stream function. The overall impacts from the three tropical ocean basins causes a $4.3 \pm 6.0^{\circ}$ westward shift of the west edge (Fig. $4 \mathrm{~g}$ ), a $10.0 \pm 8.9^{\circ}$ shift of the center (Fig. 4h), and a $7.3 \pm 5.6^{\circ}$ shift of the east edge (Fig. 4i) of the PWC. The simulated movement of the west edge (Fig. 4g) is relatively weaker than that in the reanalysis (Fig. 1c). This difference is also obvious in the anomalous patterns of the stream function between the reanalysis (Fig. 1a) and the CAM5 results (Fig. 4a).

\section{Physical processes involved in the westward shift}

As revealed by many previous studies, the tropical SST anomalies contribute to the atmospheric circulation variability primarily by driving the deep atmospheric convection (Chiang and Zebiak 2000; Choi et al. 2015) and the associated Gill-Matsuno-type atmospheric circulation adjustment (Gill 1980).

The atmospheric response to the entire tropical SST forcing is dominated by deep convection over the western Pacific and subsidence over the central Pacific, together with ascent over the Atlantic and the Indian basin (Fig. 5c). The wind response at the surface is dominated by an anomalous easterly over the central-western Pacific and a westerly over the eastern Pacific (Figs. 3b, $5 \mathrm{a})$, well reproducing the observed surface wind changes (Fig. 3a).

The La Niña-like SST gradient over the tropical Pacific (Fig. 2a) contributes to both the deep convection over the western Pacific and the subsidence over the central Pacific (Fig. 5g), associated with a westward wind anomaly over the central-eastern Pacific (Figs. 3e, 5e). These circulation changes intensify the PWC and shift the center of the stream function to the west (Fig. 4e).

The SST warming over both the Atlantic and the Indian Ocean generates regional deep convection (Fig. 5d, h) and thus Gill-Matsuno circulations (Fig. 5b, f) with the one induced by the Atlantic being stronger. The Gill-Matsuno pattern induced by the Atlantic warming (Fig. 5b) involves anomalous westerlies over the eastern Pacific, together with a long Kelvin wave tail which leads to broad easterly wind anomalies over the central-western Pacific (Fig. 3d). The Atlantic warming-induced deep convection also drives anomalous 


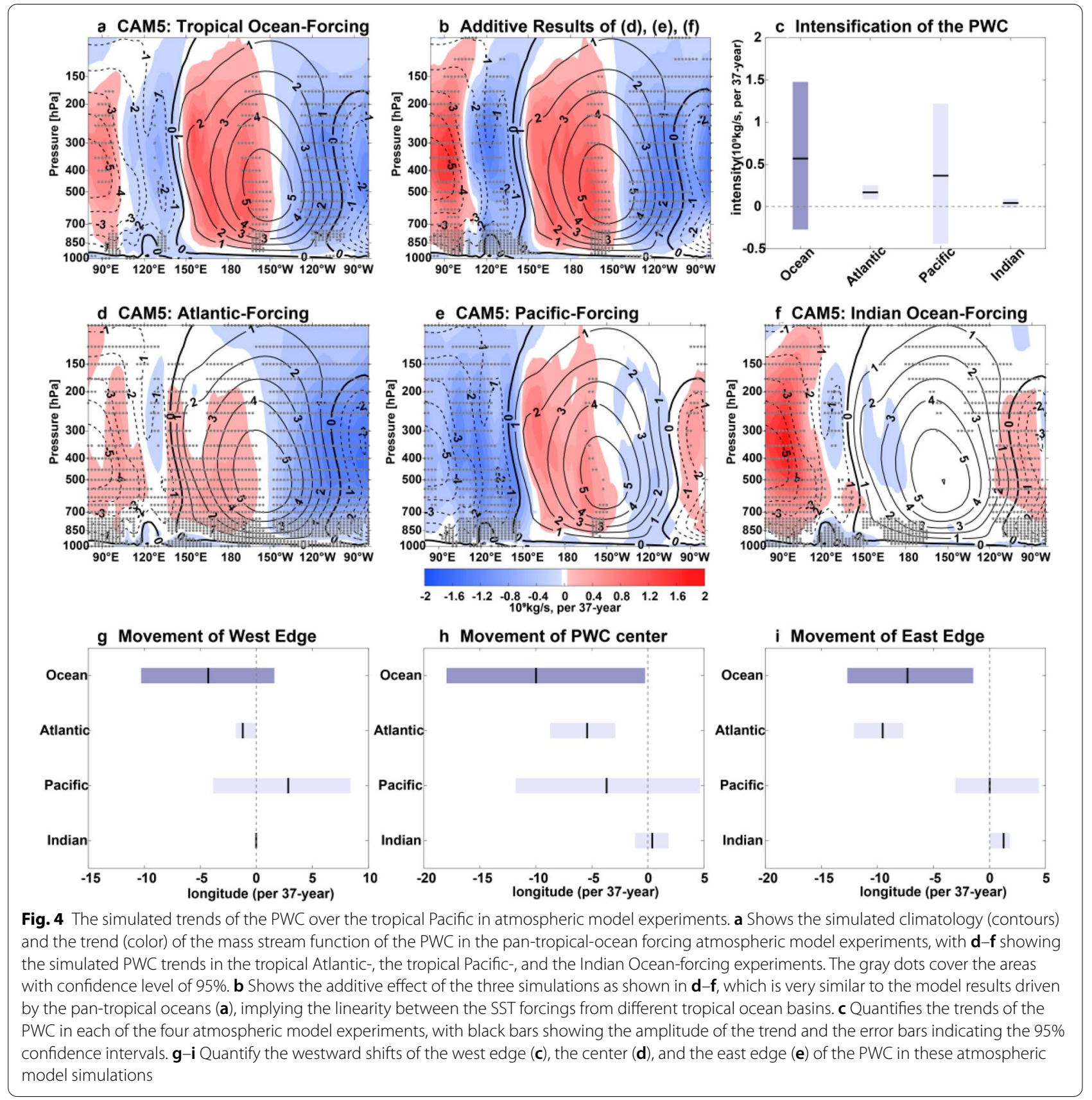

easterlies over the eastern Pacific upper troposphere (Fig. 5d), further contributing to the subsidence over the central Pacific. These circulation changes weaken the PWC stream function over the eastern Pacific (Fig. 4d) and contribute to its westward shift.

The surface wind anomalies induced by the Atlantic (Fig. 4d), the Pacific (Fig. 4e) and the Indian Ocean (Fig. 4f) work together linearly (Fig. 4c), leading to the anomalous easterlies over the central-western Pacific and westerlies over the eastern Pacific (Fig. 4b), well agreeing with the observed changes (Fig. 4a) and contributing to the movement of the PWC.

\section{The role of the inter-basin interactions}

Recent studies highlight the importance of the inter-basin interactions in triggering the tropical climate variability (Cai et al. 2019). We thus further investigate the roles of the inter-basin interactions triggered by the Atlantic (Fig. 6a), the Pacific (Fig. 6b), and the Indian Ocean (Fig. 6c) in driving the recently observed movement of 


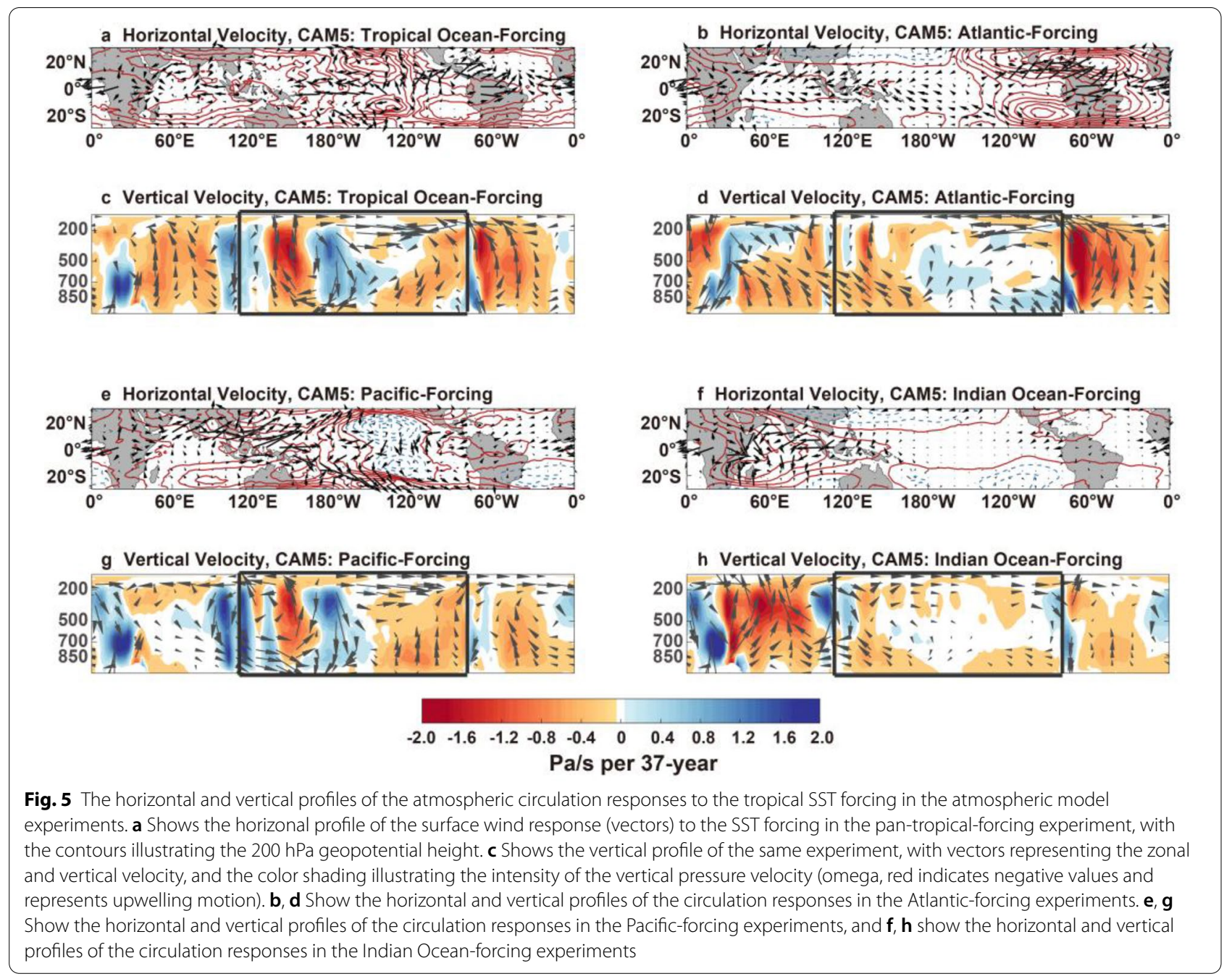

the PWC by performing pacemaker experiments using CESM coupled model. The earth system model involves the coupling processes between the ocean and the atmosphere, allowing the SST anomaly over one ocean basin to adjust the SST over others.

Simulation results show that the Atlantic-induced inter-basin interactions well reproduces both the intensification and the westward shift of the PWC (Fig. 6a), with both the amplitude $(0.47 \pm 0.22) \times 10^{9} \mathrm{~kg} / \mathrm{s}$, Fig. $\left.6 \mathrm{~d}\right)$ and the movement $\left(10.0 \pm 3.7^{\circ}, 11.7 \pm 2.8^{\circ}\right.$, and $5.2 \pm 1.1^{\circ}$ for different measurements, Fig. $6 \mathrm{e}-\mathrm{g}$ ) closely resembling those in observations (Fig. 1b-e). The Pacific and the Indian Ocean SST variabilities (Fig. 6b, c) also trigger an intensification and a shift of the PWC, albeit with relatively weaker model responses. In the pacemaker simulation, the Atlantic-induced westward shift, especially for the west edge of the PWC is larger than that of the Atmospheric model simulated PWC shift driven by the SST changes of the entire three ocean basins, with the former more similar to the observed trend. One possibility is that the Atlantic-induced off-equatorial SST changes may contribute to the shift of the PWC, which may not well simulate in the tropical ocean-forcing AGCM simulation. In addition, the pacemaker simulation may better simulate the nonlinearity of the tropical ocean-atmospheric interaction processes. These issues require further investigation.

The tropical Atlantic warming during the modern satellite era may generate regional deep convection and thus a Gill-Matsuno-type response over the entire tropics (Fig. 5b), heating the Indian Ocean and the western Pacific through the wind-evaporation-SST effect (Xie and Philander 1994) and the cloud feedback (Sun et al. 2017), and cooling the eastern Pacific through the adjustment of the PWC (Ham et al. 2013; McGregor et al. 2014). This Atlantic-induced pan-tropical SST pattern (Fig. 2b) is more similar to the observed SST trend (Fig. 2a) than that triggered by the Pacific (Fig. 2c) and 


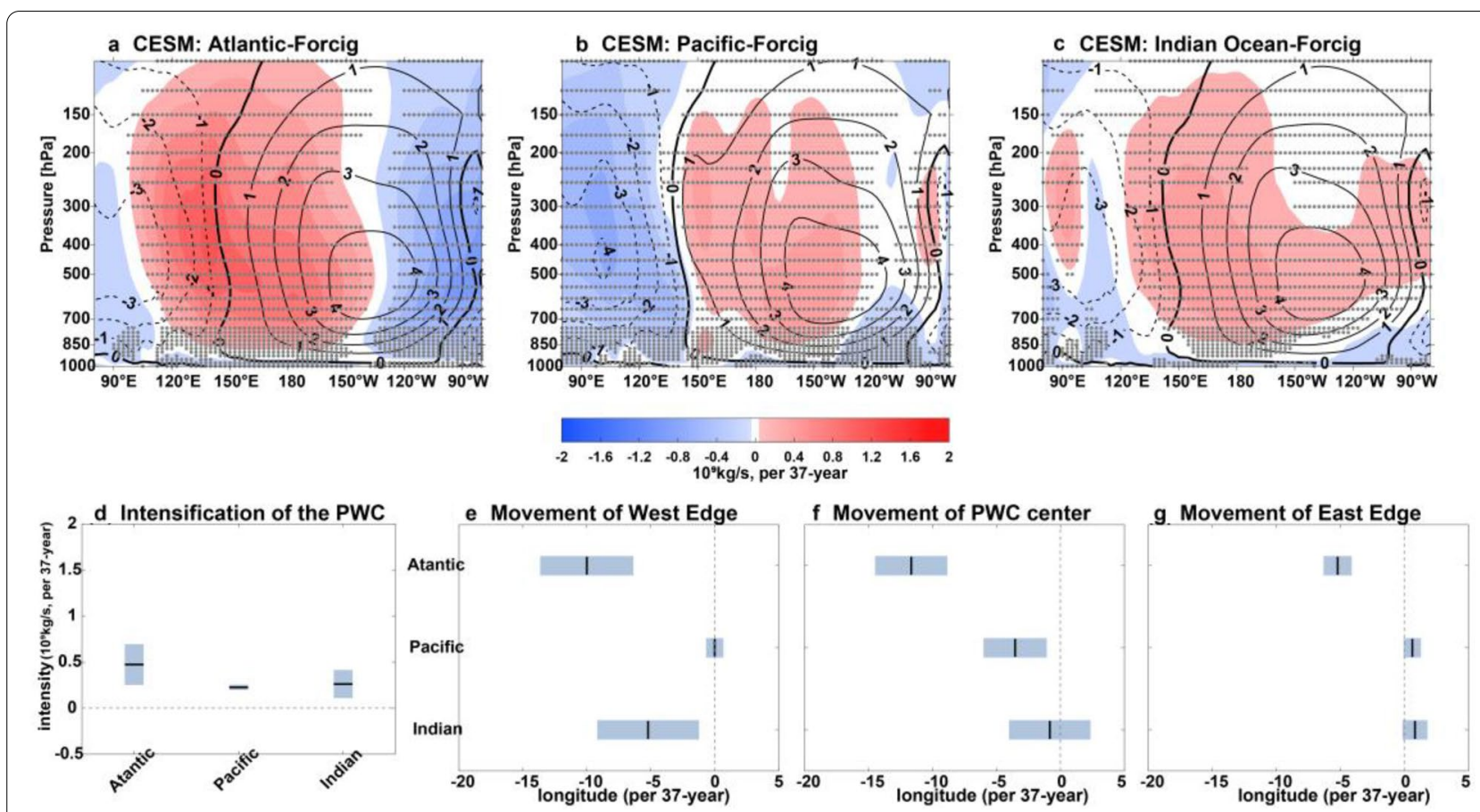

Fig. 6 The simulated trends of the PWC in the pacemaker experiments with the earth system model. a Shows the simulated climatology (contours) and the trend (color shading) of the mass stream function of PWC in the Atlantic-forcing pacemaker experiments, with $\mathbf{b}$, $\mathbf{c}$ showing the simulated PWC trends in the Pacific-, and the Indian Ocean-forcing experiments. The gray dots cover the areas with confidence level of 95\%. d Quantifies the trends of the PWC in each of the three pacemaker experiments, with black bars showing the amplitude of the trend and the error bars indicating its $95 \%$ confidence intervals. e- $\mathbf{g}$ Quantify the westward shifts of the west edge (c), the center of (d), and the east edge (e) of the PWC in these experiments

the Indian Ocean (Fig. 2d). It thus further drives an atmospheric change closely resembling the observed PWC trends.

\section{Conclusion and discussion}

During the modern satellite era since 1979, the PWC was strengthened (L'Heureux et al. 2013) and experienced a significant westward shift (Williams and Funk 2011; Ma and Zhou 2016), which is opposite to its expected trend under greenhouse gas warming (Held and Soden 2006). Previous studies mainly attributed the change in the PWC to the natural variability of the tropical ocean, in particular the phase change of the IPO (Kim and Ha 2018; Chung et al. 2019).

In this study, we investigate the role of the tropical SST forcing and the inter-basin interaction in triggering the westward shift of the PWC. We quantify the intensification of the PWC by zonally and vertically averaging the zonal mass stream function, and measure its movements through examining the longitudes of the west edge, the center, and the east edge of the stream function. Model experiments confirm the importance of the tropical Pacific SST variability in strengthening and shifting the PWC during the satellite era. Moreover, we found that the tropical Atlantic warming plays a crucial role in driving the westward shift of the PWC. The direct effect of the Atlantic warming includes a regional deep convection and a Gill-Matsuno-type circulation change over the entire tropical atmosphere, which strengthens the trade winds over the central-western Pacific and drives a westerly wind anomaly over the eastern Pacific, associated with subsidence over the central Pacific. These Atlanticinduced atmospheric circulation changes strengthen the PWC over the western Pacific but weaken it over the eastern Pacific, causing a westward shift of the PWC. Experiments using coupled earth system model further demonstrate that the Atlantic-induced pan-tropical SST pattern intensifies the PWC by $0.47 \times 10^{9} \mathrm{~kg} / \mathrm{s}$ and shift it to the west by $11.7^{\circ}$ (center), highly resembling the observed PWC changes.

The PWC is a key component of the global climate system. It actively interacts with the tropical Pacific SST on intra-seasonal to multi-decadal time scales, driving the precipitation variability over the entire tropics, and mediating the interactions between different tropical basins, and between the tropics and mid-/high-latitudes. The results revealed in this study better clarify the interactions between the tropical Atlantic SST variability (as 
well as that of the Indian Ocean and the Pacific) and the movement of the PWC, which deepens our understanding of the natural variability in the tropical and the global climate system. Considering that the intensity and the movement of the PWC are tightly linked to both the natural variability and anthropogenic forcing, our study also has broad implication in the projection of the earth climate system.

\section{Abbreviations}

AMO: Atlantic multi-decadal oscillation; CAM5: Community Atmospheric Model version 5; CMIP5: The Coupled Model Intercomparison Project phase 5; PWC: Pacific Walker circulation; SST: Sea surface temperature.

\section{Supplementary Information}

The online version contains supplementary material available at https://doi. org/10.1186/s40562-021-00180-0.

\section{Additional file 1: Figure S1. The climatology (contour) and changes} (color) of the Pacific Walker circulation (PWC) in six reanalysis datasets: a the 20 century reanalysis; $\mathbf{b}$ the ERA-interim; $\mathbf{c}$ the JRA55; $\mathbf{d}$ the MERRA; $\mathbf{e}$ the MERRA2; and $\mathbf{f}$ the NCEP2. The gray dots cover the areas with significance level $>95 \%$. Figure $\mathbf{S}$. The climatology (contour) and changes (color) of the surface zonal wind (PWC) in six reanalysis datasets: $\mathbf{a}$ the 20 century reanalysis; $\mathbf{b}$ the ERA-interim; $\mathbf{c}$ the JRA55; $\mathbf{d}$ the MERRA; $\mathbf{e}$ the MERRA2; and $\mathbf{f}$ the NCEP2. The dots cover the areas with significance level $>95 \%$. Figure $\mathbf{S 3}$. The westward shift of the surface easterlies over the equatorial Pacific in reanalyses, atmospheric model experiments, and coupled model experiments. a Quantifies the westward shift of the surface zonal wind in the multi-reanalysis-mean (MRM) and each of the six reanalyses, with black bars showing the amplitude and the error bars showing the $95 \%$ confidence intervals. b, c Quantify the westward shifts in the atmospheric model experiments (b) and the pacemaker experiments (c). Figure S4. The observed and simulated trends of the velocity potential at $1000 \mathrm{hPa}$ over the tropical Pacific. a Shows the velocity potential climatology (contours) and its trend (color) from 1979 to 2015 in the ensemblemean of six reanalysis datasets. The gray dots represent the areas with confidence level of $95 \%$. $\mathbf{b}$ Shows the simulated velocity potential trend in the pan-tropical-ocean forcing atmospheric model experiments, with $\mathbf{d - f}$ showing the simulated velocity potential trends in the tropical Atlantic-, the tropical Pacific-, and the Indian Ocean-forcing experiments. c Shows the sum of results in $\mathbf{d}-\mathbf{f}$. Convergence center (purple) also shows the sign of westward-shifting, consistent with the results of surface zonal wind. Figure S5. The vertical profiles of the atmospheric circulation responses to the tropical SST forcing in the atmospheric model experiments. a-d Same as Fig. 5c, d, g, h but with confidence level of 95\% (black dots).

\section{Acknowledgements}

Xichen Li and Xinyue Wang were supported by the National Key Research and Development Program of China (Grant No. 2016YFA0601802), the Key Research Program of Frontier Sciences, CAS (Grant No. ZDBS-LY-DQC010) and the National Natural Science Foundation of China (Grant No. 41676190 and No. 41976193).

\section{Authors' contributions}

$X \mathrm{~L}$ initiated the idea of this study and wrote the manuscript. Other authors contributed to the data analysis. All authors read and approved the final manuscript.

\section{Availability of data and materials}

The reanalysis datasets used in this study were downloaded from National Center for Atmospheric Research (https://rda.ucar.edu/). The Modern-Era Retrospective analysis for Research (MERRA) are from National Aeronautics and Space Administration (https://disc.gsfc.nasa.gov/datasets?page=1\&keywo rds=merra). The HadISST is download from Climate Prediction Center (https:// www.metoffice.gov.uk/hadobs/hadisst/).

\section{Declarations}

\section{Competing interests}

The authors declare that they have no competing interests.

\section{Author details}

${ }^{1}$ Institute of Atmospheric Physics, Chinese Academy of Sciences, Beijing, China. ${ }^{2}$ State Key Laboratory of Satellite Ocean Environment Dynamics, Second Institute of Oceanography, Ministry of Natural Resources, Hangzhou, China. ${ }^{3}$ University of Chinese Academy of Sciences, Beijing, China. ${ }^{4}$ Southern Marine Science and Engineering Guangdong Laboratory (Zhuhai), Zhuhai, China. ${ }^{5}$ School of Oceanography, Shanghai Jiao Tong University, Shanghai, China. ${ }^{6}$ NOAA Geophysical Fluid Dynamics Laboratory, Princeton, NJ 08540, USA. ${ }^{7}$ Center for Climate Change Prediction Research, Ewha Womans University, Seoul, South Korea.

Received: 21 January 2021 Accepted: 18 March 2021

Published online: 16 April 2021

\section{References}

Alexander MA, Bladé I, Newman M, Lanzante JR, Lau NC, Scott JD (2002) The atmospheric bridge: the influence of ENSO teleconnections on air-sea interaction over the global oceans. J Clim 15(16):2205-2231

Bayr T, Dommenget D, Martin T, Power SB (2014) The eastward shift of the Walker circulation in response to global warming and its relationship to ENSO variability. Clim Dyn 43(9-10):2747-2763

Bjerknes J (1969) Atmospheric teleconnections from the equatorial Pacific. Mon Weather Rev 97(3):163-172

Booth BB, Dunstone NJ, Halloran PR, Andrews T, Bellouin N (2012) Aerosols implicated as a prime driver of twentieth-century North Atlantic climate variability. Nature 484(7393):228-232

Cai W, Wu L, Lengaigne M, Li T, McGregor S, Kug JS et al (2019) Pantropical climate interactions. Science 363(6430):eaav4236

Chiang JC, Zebiak SE (2000) Surface wind over tropical oceans: diagnosis of the momentum balance, and modeling the linear friction coefficient. J Clim 13(10):1733-1747

Choi KY, Vecchi GA, Wittenberg AT (2015) Nonlinear zonal wind response to ENSO in the CMIP5 models: roles of the zonal and meridional shift of the ITCZ/SPCZ and the simulated climatological precipitation. J Clim 28(21):8556-8573

Chung ES, Timmermann A, Soden BJ, Ha KJ, Shi L, John VO (2019) Reconciling opposing Walker circulation trends in observations and model projections. Nat Clim Change 9(5):405-412

Compo GP, Whitaker JS, Sardeshmukh PD, Matsui N, Allan RJ, Yin X et al (2011) The twentieth century reanalysis project. Q J R Meteorol Soc 137(654): $1-28$

De Boisséson E, Balmaseda MA, Abdalla S, Källén E, Janssen PAEM (2014) How robust is the recent strengthening of the tropical Pacific trade winds? Geophys Res Lett 41(12):4398-4405

Dee DP, Uppala SM, Simmons AJ, Berrisford P, Poli P, Kobayashi S et al (2011) The ERA-Interim reanalysis: configuration and performance of the data assimilation system. Q J R Meteorol Soc 137(656):553-597

DiNezio PN, Vecchi GA, Clement AC (2013) Detectability of changes in the Walker circulation in response to global warming. J Clim 26(12):4038-4048

England MH, McGregor S, Spence P, Meehl GA, Timmermann A, Cai W et al (2014) Recent intensification of wind-driven circulation in the Pacific and the ongoing warming hiatus. Nat Clim Change 4(3):222-227

Gill AE (1980) Some simple solutions for heat-induced tropical circulation. Q J R Meteorol Soc 106(449):447-462

Ham YG, Kug JS, Park JY, Jin FF (2013) Sea surface temperature in the north tropical Atlantic as a trigger for El Niño/southern oscillation events. Nat Geosci 6(2):112-116

Held IM, Soden BJ (2006) Robust responses of the hydrological cycle to global warming. J Clim 19(21):5686-5699 
Horel JD, Wallace JM (1981) Planetary-scale atmospheric phenomena associated with the southern oscillation. Mon Weather Rev 109(4):813-829

Hu D, Wu L, Cai W, Gupta AS, Ganachaud A, Qiu B et al (2015) Pacific western boundary currents and their roles in climate. Nature 522(7556):299-308

Hurrell JW, Holland MM, Gent PR, Ghan S, Kay JE, Kushner PJ et al (2013) The community earth system model: a framework for collaborative research. Bull Am Meteorol Soc 94(9):1339-1360

Kanamitsu M, Ebisuzaki W, Woollen J, Yang SK, Hnilo JJ, Fiorino M, Potter GL (2002) Ncep-doe amip-ii reanalysis (r-2). Bull Am Meteorol Soc 83(11):1631-1644

Kim BH, Ha KJ (2018) Changes in equatorial zonal circulations and precipitation in the context of the global warming and natural modes. Clim Dyn 51(11-12):3999-4013

Knutson TR, Manabe S (1995) Time-mean response over the tropical Pacific to increased $\mathrm{CO}_{2}$ in a coupled ocean-atmosphere model. J Clim 8(9):2181-2199

Kobayashi S, Ota Y, Harada Y, Ebita A, Moriya M, Onoda H, Onogi K, Kamahori H, Kobayashi C, Endo H, Miyaoka K, Takahashi K (2015) The JRA-55 reanalysis: general specifications and basic characteristics. J Meteorol Soc Jpn 93(1):5-48. https://doi.org/10.2151/jmsj.2015-001

Kosaka Y, Xie SP (2013) Recent global-warming hiatus tied to equatorial Pacific surface cooling. Nature 501(7467):403-407

Kucharski F, Kang IS, Farneti R, Feudale L (2011) Tropical Pacific response to 20th century Atlantic warming. Geophys Res Lett. https://doi.org/10. 1029/2010GL046248

Kucharski F, Ikram F, Molteni F, Farneti R, Kang IS, No HH et al (2016) Atlantic forcing of Pacific decadal variability. Clim Dyn 46(7-8):2337-2351

L'Heureux ML, Lee S, Lyon B (2013) Recent multidecadal strengthening of the Walker circulation across the tropical Pacific. Nat Clim Change 3(6):571-576

Lee T, Waliser DE, Li JLF, Landerer FW, Gierach MM (2013) Evaluation of CMIP3 and CMIP5 wind stress climatology using satellite measurements and atmospheric reanalysis products. J Clim 26(16):5810-5826

Li G, Ren B (2012) Evidence for strengthening of the tropical Pacific Ocean surface wind speed during 1979-2001. Theor Appl Climatol 107(1-2):59-72

Li X, Xie SP, Gille ST, Yoo C (2016) Atlantic-induced pan-tropical climate change over the past three decades. Nat Clim Change 6(3):275-279

Lindzen RS, Nigam S (1987) On the role of sea surface temperature gradients in forcing low-level winds and convergence in the tropics. J Atmos Sci 44(17):2418-2436

Luo JJ, Sasaki W, Masumoto Y (2012) Indian Ocean warming modulates Pacific climate change. Proc Natl Acad Sci 109(46):18701-18706

Ma S, Zhou T (2016) Robust strengthening and westward shift of the tropical Pacific Walker circulation during 1979-2012: a comparison of 7 sets of reanalysis data and 26 CMIP5 models. J Clim 29(9):3097-3118

McGregor S, Timmermann A, Stuecker MF, England MH, Merrifield M, Jin FF, Chikamoto Y (2014) Recent Walker circulation strengthening and Pacific cooling amplified by Atlantic warming. Nat Clim Change 4(10):888-892

Meehl GA, Hu A, Arblaster JM, Fasullo J, Trenberth KE (2013) Externally forced and internally generated decadal climate variability associated with the interdecadal Pacific oscillation. J Clim 26(18):7298-7310

Merrifield MA (2011) A shift in western tropical Pacific sea level trends during the 1990s. J Clim 24(15):4126-4138

Neale RB, Richter J, Park S, Lauritzen PH, Vavrus SJ, Rasch PJ, Zhang M (2013) The mean climate of the community atmosphere model (CAM4) in forced SST and fully coupled experiments. J Clim 26(14):5150-5168

Power SB, Kociuba G (2011) What caused the observed twentieth-century weakening of the Walker circulation? J Clim 24(24):6501-6514

Rasmusson EM, Carpenter TH (1982) Variations in tropical sea surface temperature and surface wind fields associated with the southern oscillation/El Niño. Mon Weather Rev 110(5):354-384

Rayner NAA, Parker DE, Horton EB, Folland CK, Alexander LV, Rowell DP et al (2003) Global analyses of sea surface temperature, sea ice, and night marine air temperature since the late nineteenth century. J Geophys Res Atmos. https://doi.org/10.1029/2002JD002670

Rienecker MM, Suarez MJ, Gelaro R, Todling R, Bacmeister J, Liu E et al (2011) MERRA: NASA's modern-era retrospective analysis for research and applications. J Clim 24(14):3624-3648

Richard GO (1987) Statistical methods for environmental pollution monitoring. Wiley

Ruprich-Robert Y, Msadek R, Castruccio F, Yeager S, Delworth T, Danabasoglu G (2017) Assessing the climate impacts of the observed Atlantic multidecadal variability using the GFDL CM2. 1 and NCAR CESM1 global coupled models. J Clim 30(8):2785-2810

Schlesinger ME, Ramankutty N (1994) An oscillation in the global climate system of period 65-70 years. Nature 367(6465):723-726

Seager R, Cane M, Henderson N, Lee DE, Abernathey R, Zhang H (2019) Strengthening tropical Pacific zonal sea surface temperature gradient consistent with rising greenhouse gases. Nat Clim Change 9(7):517-522

Sen PK (1968) Estimates of the regression coefficient based on Kendall's tau. J Am Stat Assoc 63(324):1379-1389

Sun C, Kucharski F, Li J, Jin FF, Kang IS, Ding R (2017) Western tropical Pacific multidecadal variability forced by the Atlantic multidecadal oscillation. Nat Commun 8(1):1-10

Timmermann A, An SI, Kug JS, Jin FF, Cai W, Capotondi A et al (2018) El Niñosouthern oscillation complexity. Nature 559(7715):535-545

Tokinaga H, Xie SP, Deser C, Kosaka Y, Okumura YM (2012) Slowdown of the Walker circulation driven by tropical Indo-Pacific warming. Nature 491 (7424):439-443

Vecchi GA, Soden BJ, Wittenberg AT, Held IM, Leetmaa A, Harrison MJ (2006) Weakening of tropical Pacific atmospheric circulation due to anthropogenic forcing. Nature 441(7089):73-76

Wang C (2006) An overlooked feature of tropical climate: inter-Pacific-Atlantic variability. Geophys Res Lett. https://doi.org/10.1029/2006GL026324

Wang B, Liu J, Kim HJ, Webster PJ, Yim SY, Xiang B (2013) Northern Hemisphere summer monsoon intensified by mega-El Nino/southern oscillation and Atlantic multidecadal oscillation. Proc Natl Acad Sci USA 110:5347-5352

Williams AP, Funk C (2011) A westward extension of the warm pool leads to a westward extension of the Walker circulation, drying eastern Africa. Clim Dyn 37(11-12):2417-2435

Xie SP, Philander SGH (1994) A coupled ocean-atmosphere model of relevance to the ITCZ in the eastern Pacific. Tellus A 46(4):340-350

Xie SP, Deser C, Vecchi GA, Ma J, Teng H, Wittenberg AT (2010) Global warming pattern formation: sea surface temperature and rainfall. J Clim 23(4):966-986

Yu B, Zwiers FW (2010) Changes in equatorial atmospheric zonal circulations in recent decades. Geophys Res Lett. https://doi.org/10.1029/2009GL0420 71

Zhang R, Delworth TL (2007) Impact of the Atlantic multidecadal oscillation on North Pacific climate variability. Geophys Res Lett. https://doi.org/10. 1029/2007GL031601

Zhang R, Delworth TL (2009) A new method for attributing climate variations over the Atlantic Hurricane Basin's main development region. Geophys Res Lett. https://doi.org/10.1029/2009GL037260

Zhang L, Karnauskas KB (2017) The role of tropical interbasin SST gradients in forcing Walker circulation trends. J Clim 30(2):499-508

Zhang M, Song H (2006) Evidence of deceleration of atmospheric vertical overturning circulation over the tropical Pacific. Geophys Res Lett. https:// doi.org/10.1029/2006GL025942

\section{Publisher's Note}

Springer Nature remains neutral with regard to jurisdictional claims in published maps and institutional affiliations. 